\title{
The production of renewable energy in the form of methane using electrolytic hydrogen generation
}

\author{
Koji Hashimoto ${ }^{1 *}$, Naokazu Kumagai ${ }^{2}$, Koichi Izumiya ${ }^{2}$, Hiroyuki Takano ${ }^{2}$ and Zenta Kato ${ }^{1}$
}

\begin{abstract}
An extrapolation of the world energy consumption from 1990 to 2010 indicates a complete exhaustion of the world reserves of oil, natural gas, uranium, and coal by 2043, 2047, 2051, and 2055, respectively. For the survival of all people in the whole world, intermittent and fluctuating electricity generated from renewable energy should be supplied in the form of usable fuel. We have been working on research and development of global $\mathrm{CO}_{2}$ recycling for the use of renewable energy produced via electrolytic hydrogen generation in the form of methane. We created energy-saving cathodes for $\mathrm{H}_{2}$ production, anodes for $\mathrm{O}_{2}$ evolution without chlorine formation in seawater electrolysis, and catalysts for methanation of $\mathrm{CO}_{2}$ by the reaction with $\mathrm{H}_{2}$, and built pilot plants on an industrial scale. The development of new anode and cathode for alkali water electrolysis, the improvement of the anode for seawater electrolysis and the catalysts for $\mathrm{CO}_{2}$ methanation, as well as industrial applications are in progress.
\end{abstract}

\section{Review Introduction \\ The future of energy}

Over the past two decades, we have been working on research and development of a global $\mathrm{CO}_{2}$ recycling system. Now, industrial applications of global $\mathrm{CO}_{2}$ recycling are in progress. At first, let us identify problems regarding global energy in the current situation of unlimited access to energy resources, including oil, natural gas, coal, and uranium. The US Department of Energy (DOE) has collected energy-related world data over a period of 30 years (from 1980 to 2010) [1]. Based on these DOE data, Figure 1 exhibits the chronological patterns of variation in energy consumption per capita in three groups of countries as well as those of the world, USA, Japan, and China. A significant difference in the energy consumption per capita among the countries is evident. As shown in Figure 2, the $\mathrm{CO}_{2}$ emissions per capita are almost the same as the energy consumption per capita. There is no trend of decreasing energy consumption and carbon emissions per capita in developed countries except for temporary fluctuations influenced by the economic situation, for which Lehman Brothers bankruptcy in 2008 is a recent example. The energy consumption and carbon

\footnotetext{
* Correspondence: koji@imr.tohoku.ac.jp

${ }^{1}$ Tohoku Institute of Technology, Sendai 982-8577, Japan

Full list of author information is available at the end of the article
}

emission per capita of developing countries are far lower than those of developed countries. Figure 3 illustrates the relationship between the energy consumption per capita and population for three groups of countries in 2010. The population of developed countries was $17.7 \%$ of the world population consuming nearly half of the world's energy. The residents in developing countries reached $78.1 \%$ of the world population but consumed less than half of the world's energy consumption. The residents in developing countries can therefore double the current level of energy consumption per capita to approach the global average level of energy consumption. In contrast, a 77\% reduction of energy consumption per capita for US residents is required to reach an average global energy consumption level. Such a target is practically impossible to achieve. It is also impossible to reduce the energy consumption per capita by $60 \%$ on average for all developed countries and a half for Eurasian countries. Thus, the energy consumption per capita in the world will increase continuously. Moreover, the world population rose from 1980 to 2010 with an annual increase of 80 million [1]. Consequently, it is inevitable that the total world energy consumption would rise continuously.

The left side of Figure 4 shows the chronological patterns of global energy consumption for the recent 


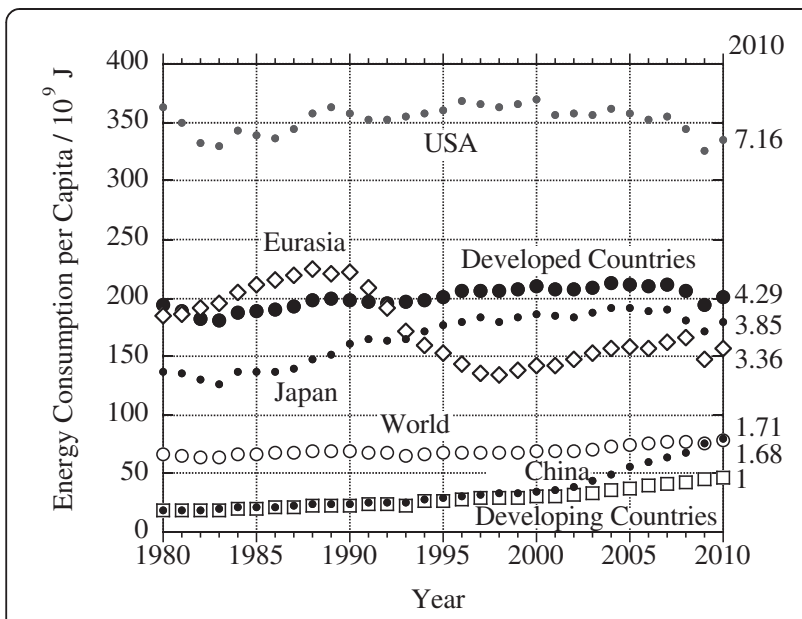

Figure 1 Change in energy consumption per capita for the world, three groups of countries, USA, China and Japan [1].

30 years [1]. The annual global energy consumption increased steadily by a factor of 1.0196 from 1990 to 2010 after the collapse of the Soviet Union. The full line prediction curve in Figure 4 was drawn by extrapolating the recent energy consumption record under the assumption of the annual rising factor of 1.0196. In Figure 4, the projected year of exhaustion is given based on the energy consumption mode of 2010 as 2043 for oil and 2047 for natural gas. If the usage of uranium as a fuel for nuclear power reactors in any country will be allowed without any limitation, the estimated uranium resource of $5.33 \mathrm{Mt}$ [2] will be exhausted in 2051. Then, in 2055, coal would be exhausted. A continued use of fossil fuels will lead to intolerable global warming owing to the greenhouse effect. The oil-producing countries should therefore use the remaining oil for their own

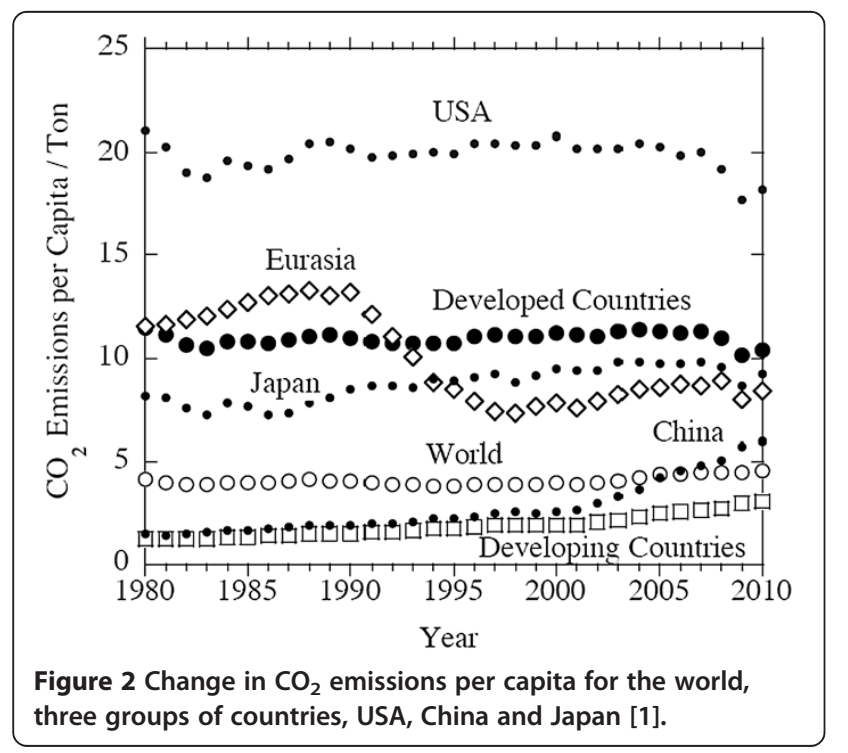

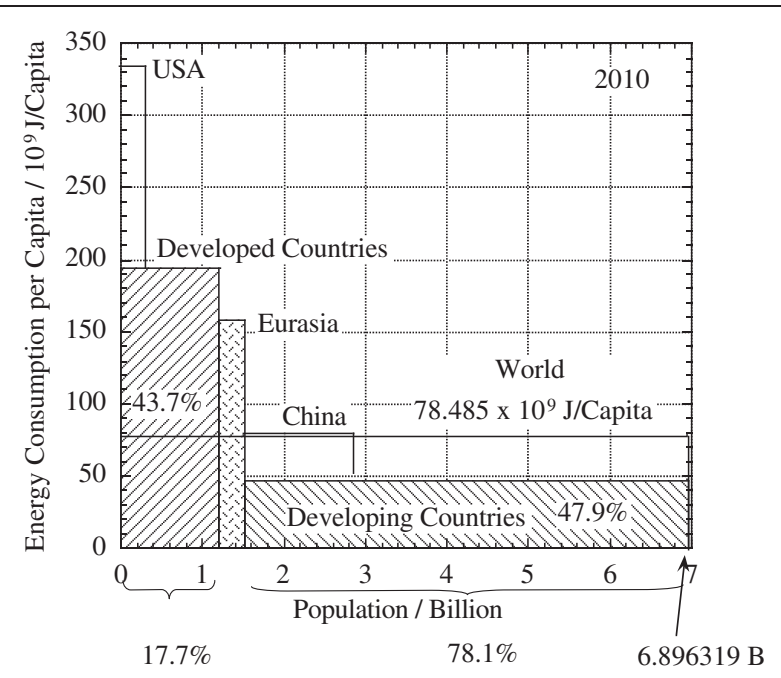

Figure 3 Relationship between energy consumption per capita and population in the three groups of countries in 2010 [1]. Although the values of developed and developing countries include those of USA and China, respectively, the values of USA and China are separately overwritten.

survival, and hence the oil supply will decline showing a maximum within 10 to 15 years. Indonesia declared on 26 January 2012 that they would place the priority for domestic oil consumption ahead of oil exportation.

For the moment, the purchase of oil, natural gas, and coal, as well as uranium has practically no trade limitation, and thus the motivation to urgently develop an economically viable system of renewable energy production remains low due to a low expectancy of immediate economic profit. However, looking straight at the reality that the available fuel resources will be exhausted around the middle of the twenty-first century and that the continued use of fossil fuel will lead to intolerable global warming, as demonstrated in Figure 5, we need to establish the technologies to use renewable energy for all people in the whole world to survive and to spread the technologies to the whole world within the next 15 years.

\section{The usage of renewable energy}

In 2010, renewable electric power, excluding hydroelectric power, reached only about $1.4 \%$ of the energy consumed in the whole world. For a long-term sustained survival of human beings over the globe, we have to substitute $100 \%$ of this energy with renewable energy. There are sufficient renewable energy sources on our planet. For example, in 2010, the total energy consumed worldwide was $538.66 \times 10^{18} \mathrm{~J}_{\text {year }}{ }^{-1}$. The corresponding amount of energy can be generated in the form of electricity by photovoltaic cells with an energy conversion efficiency of $15 \%$ in a desert area supplying a solar intensity of $1,000 \mathrm{Wm}^{-2}$ when they were operated $8 \mathrm{~h}$ per day and employed only $2.11 \%$ of the area of the main deserts 


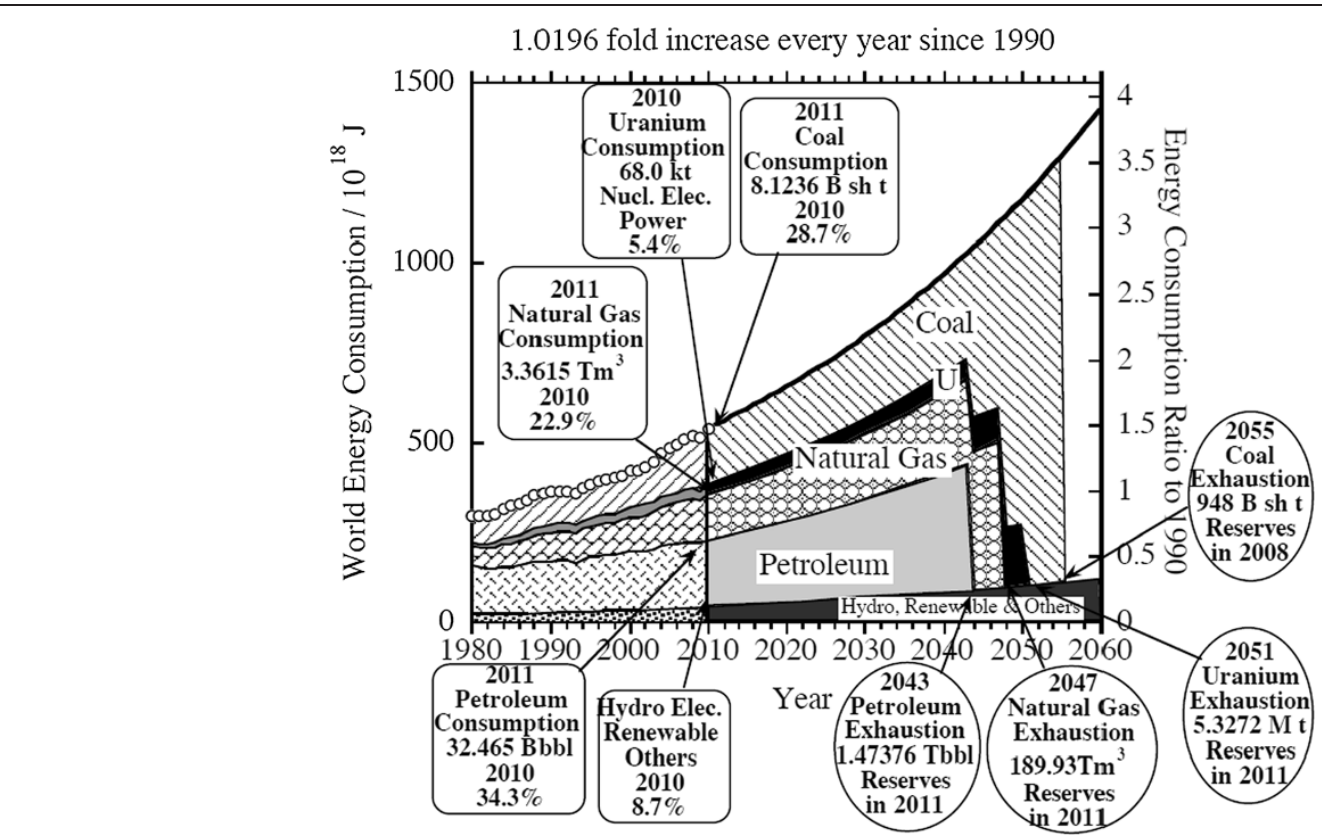

Figure 4 Change in recent energy consumption and future prospects of the world energy demand. The energy consumption over a recent period of 30 years [1] and future prospects of the world energy demand estimated under the assumption of a continued rise in the rate of energy consumption evaluated over the period from 1990 to 2010 and the anticipated years of exhaustion of world reserves of fossil fuels [1] and uranium [2].

on the Earth. This estimate is rather encouraging because it indicates that we can survive on our planet.

The technologies of converting different types of renewable energy sources to electric power have already been developed. The inherent disadvantage of renewable energy sources in general is their instability with fluctuation with time. Thus, when electricity generated by renewable energy sources is directly integrated in the

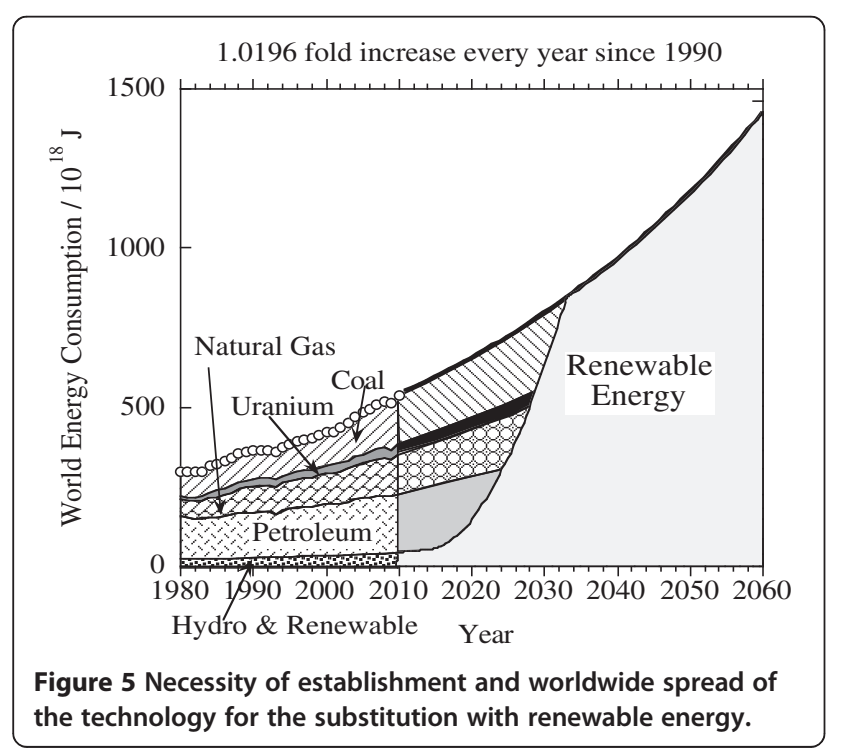

existing electricity supply network system, an undesirable frequency fluctuation of the supplied alternating current $(\mathrm{AC})$ is inevitable. In modern industry, an $\mathrm{AC}$ electric power supply with a frequency fluctuation margin of $\pm 0.2 \mathrm{~Hz}$ is claimed to be unacceptable [3]. In Japan, the frequency fluctuation margin of AC electricity supplied to the customer is set at $\pm 0.2 \mathrm{~Hz}$ by all the electric power supply companies excluding Hokkaido Electric Power Company, which sets the margin at $\pm 0.3 \mathrm{~Hz}$ [3]. According to an estimate made by Hokkaido Electric Power Company [4], the frequency error margin of $\pm 0.3 \mathrm{~Hz}$ cannot be held when electricity generated by wind exceeds $250 \mathrm{MW}$ ( $4.8 \%$ of the maximum total power in the network). As such, it is difficult to integrate electricity generated by renewable energy sources with its inherently fluctuating nature exceeding about $5 \%$ of the maximum instantaneous power output in the existing electricity supply grid. Therefore, the electric energy generated by intermittent and fluctuating renewable sources should be converted into some form of fuel.

\section{Global carbon dioxide recycling}

As early as the 1970s, we had been dreaming to supply hydrogen to all people in the whole world, generating hydrogen by seawater electrolysis using the renewable energy origin electricity. However, we understood that there exists no infrastructure for a mass transportation 
of hydrogen and no combustion technology for hydrogen. Thus, for establishing renewable-energy-fuelled communities worldwide, we need to convert the energy generated by renewable energy sources to some form of fuel material for which the combustion technology as well as the mass transportation infrastructures have been established.

More than two decades ago, the authors created a catalyst that converted $\mathrm{CO}_{2}$ and $\mathrm{H}_{2}$ to methane $\left(\mathrm{CH}_{4}\right)$ with an almost $100 \% \mathrm{CH}_{4}$ selectivity [5]. Methane is the main constituent of natural gas, for which both the efficient mass transportation infrastructures and the combustion technologies have been well established. Therefore, we proposed global $\mathrm{CO}_{2}$ recycling on the basis of the discovery of this catalyst [6]. The sequence of energy conversion in the proposed system is as follows:

(i) Energy necessary for all people in the whole world is converted to electricity from solar energy in deserts.

(ii) The electricity is used for $\mathrm{H}_{2}$ production by seawater electrolysis in plants installed along the coasts near the deserts.

(iii) $\mathrm{H}_{2}$ is converted to $\mathrm{CH}_{4}$ by the reaction with $\mathrm{CO}_{2}$ in the plants next to the electrolyzers.

(iv) Using the available transportation infrastructure, the generated $\mathrm{CH}_{4}$ is sent to the areas of consumption.

The only difference from the current practice is that $\mathrm{CO}_{2}$ should be captured from the chimney and be sent to the place where the electricity is available from renewable energy. If this is realized, we can use solar energy forever, using $\mathrm{CO}_{2}$ as the feedstock without emitting it into the atmosphere.

An industrial technology for the conversion of renewable energy sources to electricity is available, and the infrastructures for $\mathrm{CH}_{4}$ transportation and combustion technologies have been developed. Capturing of $\mathrm{CO}_{2}$ gas from the chimney has also been proven to be industrially viable. The properties of liquefied $\mathrm{CO}_{2}$ are comparable to those of liquefied petroleum gas (LPG), and therefore the transportation of the liquefied $\mathrm{CO}_{2}$ is possible. Thus, the realization of the global $\mathrm{CO}_{2}$ recycling can be performed through the establishment of the technologies to yield $\mathrm{H}_{2}$ by seawater electrolysis and to produce $\mathrm{CH}_{4}$ by the reaction of $\mathrm{H}_{2}$ with $\mathrm{CO}_{2}$.

\section{Key materials for global carbon dioxide recycling}

The key materials toward the realization of a global $\mathrm{CO}_{2}$ recycling are the cathode and anode for seawater electrolysis and a catalyst for the conversion of $\mathrm{H}_{2}$ to $\mathrm{CH}_{4}$ through the reaction with $\mathrm{CO}_{2}$.

\section{Cathode}

We need a cathode consisting of inexpensive elements and having a high activity comparable of platinum black. We have succeeded in creating active and durable alloy cathodes by electrodeposition [7]. The key elements were iron and carbon. Figure 6 presents the cathodic polarization curves of the electrodeposited metals and alloys for hydrogen formation. Nickel was stable but less active. Iron was more active than nickel, and the $\mathrm{Ni}-\mathrm{Fe}$ alloy was more active than iron. When iron and carbon were added to nickel, the activity becomes remarkably high. The change in Tafel slope ( $\partial \mathrm{E} / \partial \log i)$ suggests that the hydrogen evolution on the $\mathrm{Ni}-\mathrm{Fe}-\mathrm{C}$ alloy cathodes was mechanistically fastest. The hydrogen evolution reaction (1) consists of two series of elemental reactions $(2)+(3)$ or $(2)+(4)$ :

$$
\begin{aligned}
& 2 \mathrm{H}_{2} \mathrm{O}+2 \mathrm{e}^{-} \rightarrow \mathrm{H}_{2}+2 \mathrm{OH}^{-} \quad\left(2 \mathrm{H}^{+}+2 \mathrm{e}^{-} \rightarrow \mathrm{H}_{2}\right) \\
& \mathrm{H}_{2} \mathrm{O}+\mathrm{e}^{-} \rightarrow \mathrm{H}_{\mathrm{ads}}+\mathrm{OH}^{-} \quad\left(\mathrm{H}^{+}+\mathrm{e}^{-} \rightarrow \mathrm{H}_{\mathrm{ads}}\right) \\
& 2 \mathrm{H}_{\mathrm{ads}} \rightarrow \mathrm{H}_{2} \\
& \mathrm{H}_{\mathrm{ads}}+\mathrm{H}_{2} \mathrm{O}+\mathrm{e}^{-} \rightarrow \mathrm{H}_{2}+\mathrm{OH}^{-} \quad\left(\mathrm{H}^{+}+\mathrm{H}_{\mathrm{ads}}+\mathrm{e}^{-} \rightarrow \mathrm{H}_{2}\right)
\end{aligned}
$$

where $\mathrm{H}_{\mathrm{ads}}$ is a hydrogen atom formed by proton discharge and is adsorbed on the cathode surface. On the assumption of the coverage of $\mathrm{H}_{\mathrm{ads}}, \theta$ and the transfer coefficient $\alpha$ as $\theta<<1$ and $\alpha=1 / 2$, the rate determining reaction, the Tafel slope and corresponding electrode are summarized in Table 1 . If the formation of $\mathrm{H}_{\text {ads }}$ (2) is sufficiently fast due to the high density of the active surface sites on the cathode and due to the fast charge

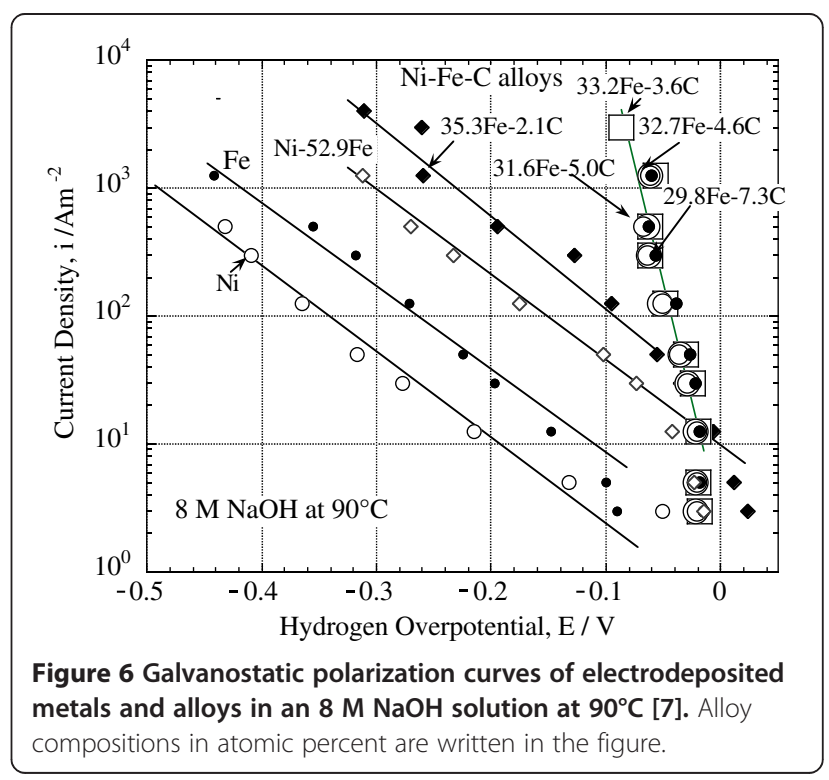


Table 1 The rate-determining reaction and Tafel slope at $90^{\circ} \mathrm{C}$

\begin{tabular}{|c|c|c|}
\hline $\begin{array}{l}\text { Rate-determining } \\
\text { reaction }\end{array}$ & 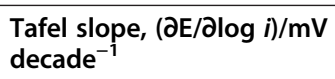 & $\begin{array}{l}\text { Electrode shown } \\
\text { in Figure } 6\end{array}$ \\
\hline (2) & 144 & $\mathrm{Ni}, \mathrm{Fe}, \mathrm{Ni}-\mathrm{Fe}$ \\
\hline (3) & 36 & $\mathrm{Ni}-\mathrm{Fe}-\mathrm{C}$ \\
\hline (4) & 48 & \\
\hline
\end{tabular}

transfer from the cathode to proton, the $\mathrm{H}_{2}$ molecule release by meeting two hydrogen atoms together (3) is the rate-determining step such as on $\mathrm{Ni}-\mathrm{Fe}-\mathrm{C}$, but if the proton discharge (2) is slower because of lower density of the active sites, the reaction (2) is the rate-determining step. Thus, we could get the $\mathrm{Ni}-\mathrm{Fe}-\mathrm{C}$ electrode with the mechanistically fastest hydrogen formation due to the high density of the active surface sites, and due to the fast charge transfer from the cathode to proton, we found that the significant charge transfer from nickel to iron by the addition of iron and carbon to nickel is responsible for the remarkable acceleration of proton discharge to form hydrogen atoms adsorbed on the cathode surface.

These cathodes with mechanistically highest activity made of Ni-based alloys or Co-based alloys [8] can be used not only for direct seawater electrolysis but also for high-temperature alkali water electrolysis.

\section{Anode materials for seawater electrolysis}

Industrial electrolysis of $\mathrm{NaCl}$ solutions in either the chlor-alkali industry or sodium hypochlorite $(\mathrm{NaClO})$ production has been conducted for the formation of chlorine $\left(\mathrm{Cl}_{2}\right)$ on the anode. However, in seawater electrolysis for massive amounts of $\mathrm{H}_{2}$ production, the $\mathrm{Cl}_{2}$ formation on the anode should be avoided. An anode material to form oxygen in place of $\mathrm{Cl}_{2}$ is required to produce $\mathrm{H}_{2}$ by seawater electrolysis. This concern has been solved by developing special anodes bearing single phase multiple oxides consisting mainly of Mn containing also Mo, W, Sn, and/or Fe as active electrocatalysts [9-12]. An example is shown in Figure 7 [10]. When $\mathrm{MnO}_{2}$ was used as the electrocatalyst, about 92\% of electricity was consumed for oxygen evolution at the current density of $1,000 \mathrm{Am}^{-2}$ in $0.5 \mathrm{M} \mathrm{NaCl}$ but $8 \%$ of electricity was employed for chlorine evolution. However, when small fractions of manganese were substituted with molybdenum, a $100 \%$ oxygen evolution was attained. An improvement of the anode led to the realization of the anode life exceeding $4,200 \mathrm{~h}$ at the current density of $1,000 \mathrm{Am}^{-2}$ in a $0.5 \mathrm{M} \mathrm{NaCl}$ solution of $\mathrm{pH} 1$ [13].

The direct seawater electrolysis for the generation of hydrogen is certainly a clean option of acquiring an energy source, but there are numerous technical problems to be solved. In terms of energy consumption at present, this direct seawater electrolysis cannot compete with the

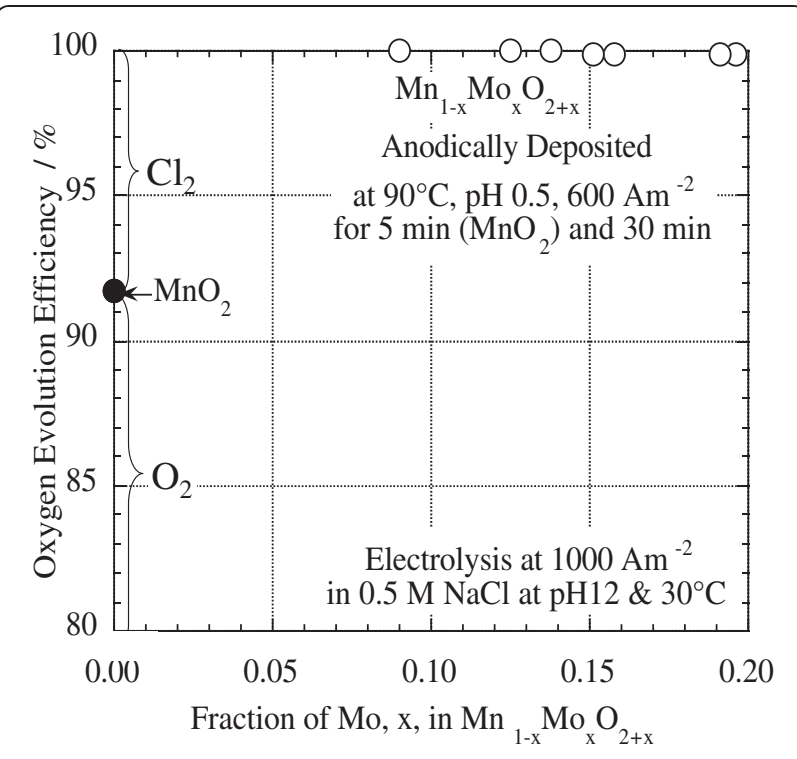

Figure 7 Oxygen evolution efficiency of $\mathrm{MnO}_{2}$ and $\mathrm{Mn}_{1-x} \mathrm{Mo}_{x} \mathrm{O}_{2+x}$ in $0.5 \mathrm{M} \mathrm{NaCl}$ of $\mathrm{pH} 12$ at $30^{\circ} \mathrm{C}$ and $1,000 \mathrm{Am}^{-2}$ [10].

high-temperature alkali water electrolysis undertaken for desalinated seawater. Therefore, at the moment, for a large-scale industrial plant, the hot alkali water electrolysis is preferred against direct seawater electrolysis. For the construction of a new hot alkali water electrolyzer, a study of an anode and a cathode attaining the mechanistically highest activities even at 6,000 $\mathrm{Am}^{-2}$ in $30 \mathrm{wt} \%$ $\mathrm{KOH}$ solution at $90^{\circ} \mathrm{C}$ is in progress.

\section{Methanation of carbon dioxide}

Catalyst for $\mathrm{CO}_{2}$ methanation Our objective was to form $\mathrm{CH}_{4}$ very rapidly by the reaction of $\mathrm{CO}_{2}$ with $\mathrm{H}_{2}$ without forming a toxic by-product such as $\mathrm{CO}$ through the reaction

$$
\mathrm{CO}_{2}+4 \mathrm{H}_{2} \rightarrow \mathrm{CH}_{4}+2 \mathrm{H}_{2} \mathrm{O}
$$

When we used amorphous $\mathrm{Ni}-\mathrm{Zr}$ alloys as the catalyst precursor for the reaction of $\mathrm{CO}_{2}$ with $\mathrm{H}_{2}$, the $\mathrm{CO}_{2}$ conversion occurred rapidly as has been demonstrated in Figure 8 [5]. The methane selectivity of the $\mathrm{Ni}-\mathrm{Zr}$ catalyst was almost $100 \%$ in the temperature range of $200^{\circ} \mathrm{C}$ to $300^{\circ} \mathrm{C}$, as shown in Figure 9 [5]. When the amorphous $\mathrm{Ni}-\mathrm{Zr}$ alloy catalyst precursor was exposed to a $\mathrm{CO}_{2}$ : $\mathrm{H}_{2}=1: 4$ mixture at a temperature in the range of $200^{\circ} \mathrm{C}$ to $300^{\circ} \mathrm{C}$, zirconium was selectively oxidized and converted to $\mathrm{ZrO}_{2}$, while the most of nickel remains in the metallic state, with a consequent formation of the catalyst consisting of nickel supported on $\mathrm{ZrO}_{2}$. In practice, such a catalyst can be produced from the amorphous $\mathrm{Ni}-\mathrm{Zr}$ alloy precursor through oxidation in air and a subsequent reduction in $\mathrm{H}_{2}$ atmosphere. At a temperature 


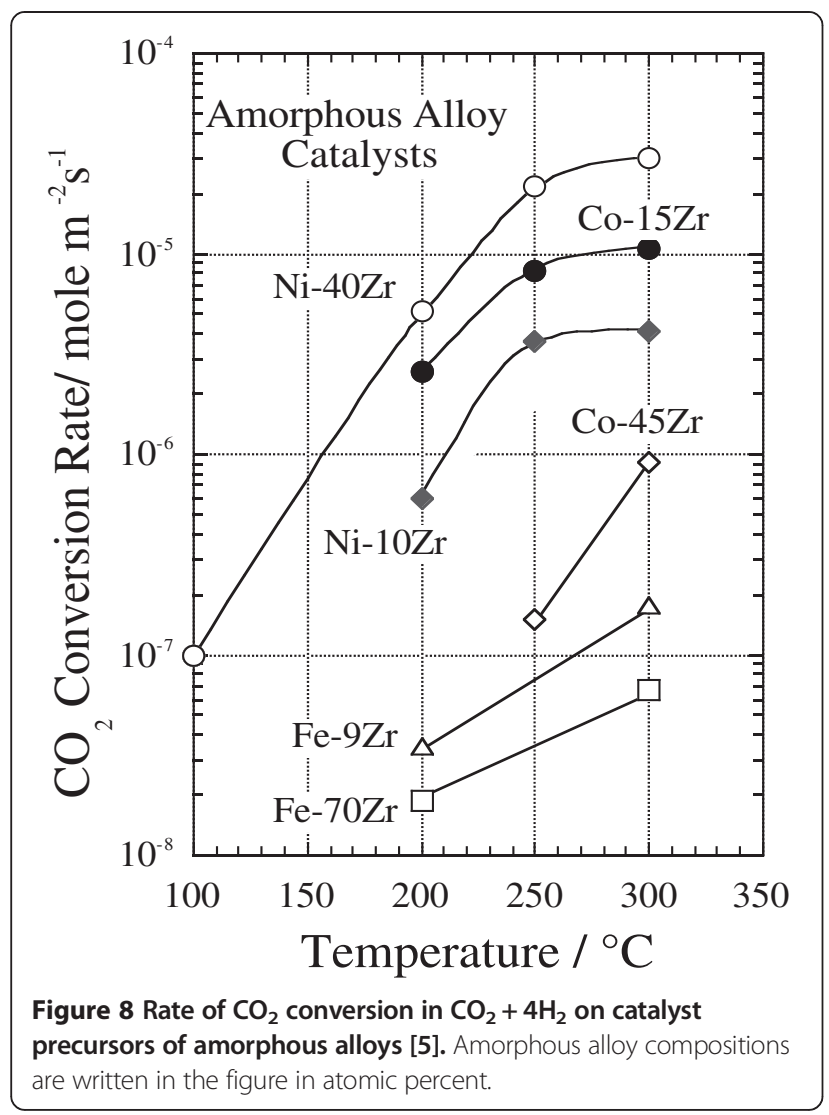

of around $200^{\circ} \mathrm{C}$ to $300^{\circ} \mathrm{C}$ for the catalytic reaction, the thermodynamically stable phase of $\mathrm{ZrO}_{2}$ is monoclinic, but a considerable fraction of tetragonal $\mathrm{ZrO}_{2}$ has been found from the amorphous Ni-Zr precursor, and Ni supported by tetragonal $\mathrm{ZrO}_{2}$ has possessed a high catalytic function [14]. The tetragonal $\mathrm{ZrO}_{2}$ has been identified as the double oxide in which $\mathrm{Ni}^{2+}$ ions have also been included during the formation of a $\mathrm{ZrO}_{2}$ lattice by the oxidation of zirconium in the $\mathrm{Ni}-\mathrm{Zr}$ alloys while occupying the lattice points of $\mathrm{Zr}^{4+}$ in the $\mathrm{ZrO}_{2}$ lattice. As a rule, the higher the nickel content in the amorphous $\mathrm{Ni}-\mathrm{Zr}$ precursor, the higher is the fraction of tetragonal $\mathrm{ZrO}_{2}$-type double oxide and the higher is the catalytic activity [15]. When the nickel content of the $\mathrm{Ni}-\mathrm{Zr}$ precursor is, however, excessively high, an unfavorable nickel agglomeration proceeds on the catalyst surface and leads to a loss of the active site of the catalyst, that is, nickel atoms on the surface of the $\mathrm{ZrO}_{2}$-type double oxide.

It is ideal if the fraction of the tetragonal $\mathrm{ZrO}_{2}$ type oxide rises without increasing the proportion of nickel in the amorphous $\mathrm{Ni}-\mathrm{Zr}$ precursor. It is known empirically that the tetragonal $\mathrm{ZrO}_{2}$-type double oxide is stabilized through a partial replacement of $\mathrm{Zr}^{4+}$ by metal ions with rare earth elements and divalent $\mathrm{Ca}^{2+}$ and $\mathrm{Mg}^{2+}$ as well as $\mathrm{Ni}^{2+}$. In fact, we managed to raise the catalytic

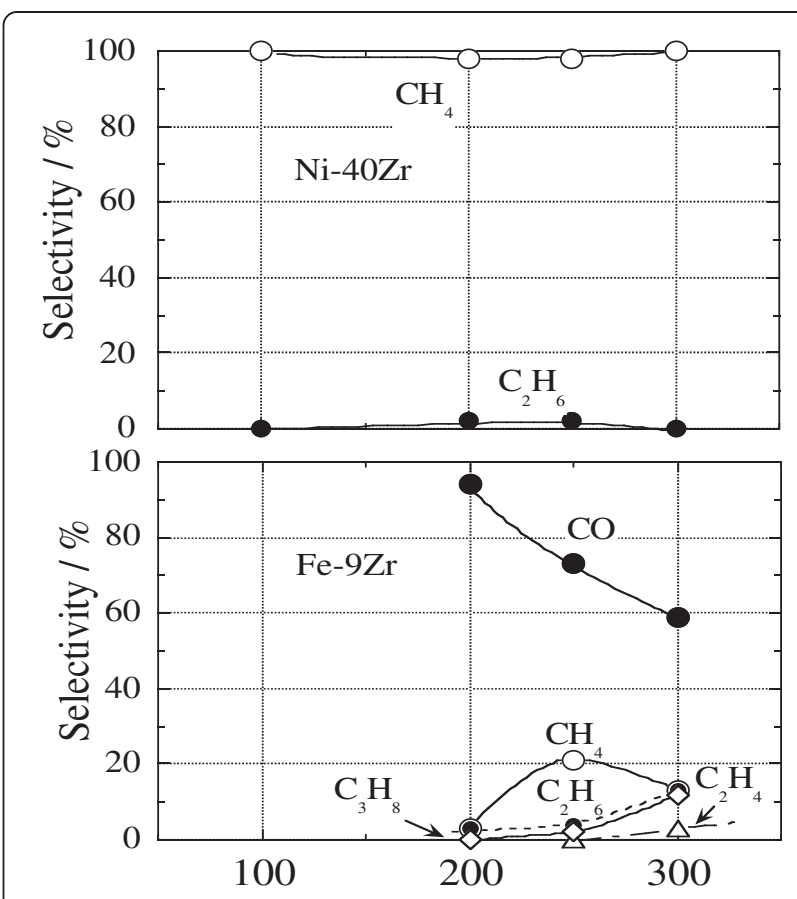

Temperature $/{ }^{\circ} \mathrm{C}$

Figure 9 The selectivity of products during a $\mathrm{CO}_{2}$ conversion in $\mathrm{CO}_{2}+4 \mathrm{H}_{2}$ on amorphous alloy catalyst precursors [5]. The products are written in the figure.

activity of the $\mathrm{Ni} /$ tetragonal $\mathrm{ZrO}_{2}$-type oxide catalyst by adding rare earth elements to the amorphous $\mathrm{Ni}-\mathrm{Zr}$ precursor, as has been illustrated in Figure 10 [16]. We [17] also demonstrated that the catalyst developed from the amorphous $\mathrm{Ni}-\mathrm{Zr}-\mathrm{Sm}$ precursor promoted the methanation of $\mathrm{CO}$ preferentially for a gas mixture of $\mathrm{CO}, \mathrm{CO}_{2}$, and $\mathrm{H}_{2}$ as shown in Figure 11.

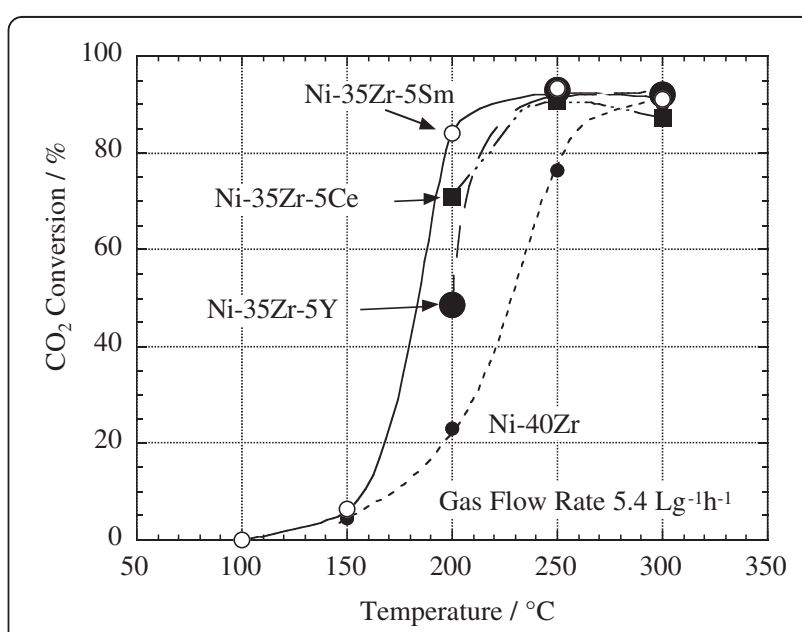

Figure $10 \mathrm{CO}_{2}$ conversion in $\mathrm{CO}_{2}+4 \mathrm{H}_{2}$ on catalyst precursors of amorphous Ni-Zr-rare earth element alloys [16]. Amorphous alloy compositions are written in the figure in atomic percent. 


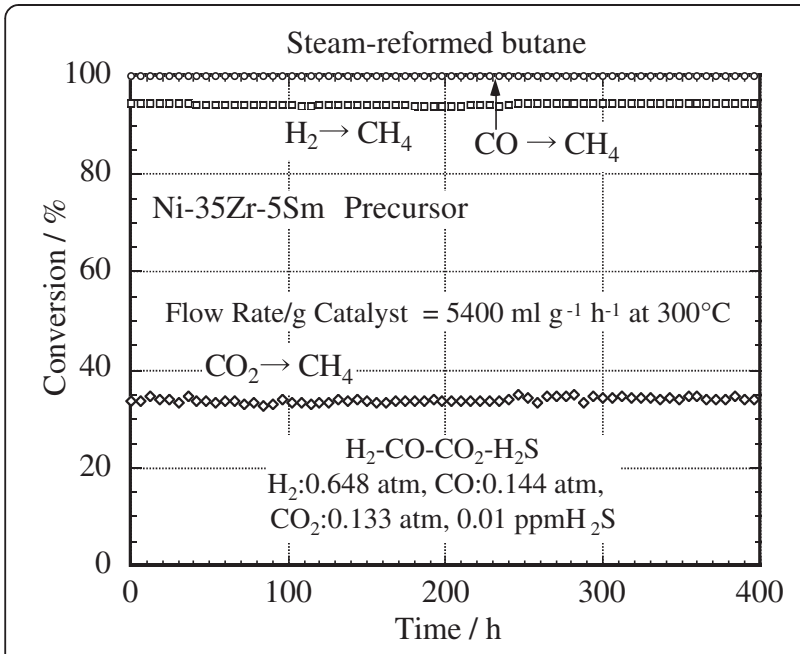

Figure 11 Conversion of the gas mixture of $\mathrm{H}_{2}-\mathrm{CO}-\mathrm{CO}_{2}$ on amorphous Ni-35Zr-5Sm alloy precursor [17].

Catalyst for mass production As has been reviewed above, it was confirmed by laboratory investigations that nickel supported by the tetragonal $\mathrm{ZrO}_{2}$-type double oxide formed from the amorphous $\mathrm{Ni}-\mathrm{Zr}$ alloy precursors was an efficient catalyst for $\mathrm{CO}_{2}$ methanation. However, in general, amorphous alloys are not suitable for mass production of an industrial catalyst. As mentioned above, the essential factor for the high catalytic activity of $\mathrm{CO}_{2}$ methanation was not the amorphous structure but the presence of the tetragonal $\mathrm{ZrO}_{2}$-type multiple oxide containing extra cations of a lower valence than $\mathrm{Zr}^{4+}$. Hence, we synthesized the tetragonal $\mathrm{ZrO}_{2}$-type double oxide by the calcination of a mixture of zirconia hydrosol with a salt of rare earth elements and then by the impregnation of nickel on the tetragonal $\mathrm{ZrO}_{2}$-type double oxide. The catalyst prepared in such way was proved to act satisfactorily as a catalyst for $\mathrm{CO}_{2}$ methanation [18].

Aiming at a further simplification of the catalyst preparation process, we calcined a mixture of zirconia hydrosol, rare earth element salt, and nickel salt to obtain a mixture of the tetragonal $\mathrm{ZrO}_{2}$-type triple oxide and $\mathrm{NiO}$. After this, surface $\mathrm{NiO}$ was reduced by $\mathrm{H}_{2}$ to prepare metallic nickel supported by the tetragonal $\mathrm{ZrO}_{2}$ type oxide. The $\mathrm{Ni}$ supported by the tetragonal $\mathrm{Zr}_{1}-x-{ }_{y} \mathrm{Sm}_{x} \mathrm{Ni}_{y} \mathrm{O}_{2}-0.5 x-y$ catalysts possessed better catalytic activity than the catalysts formed from amorphous alloys [19].

In conclusion, the proposed procedure starting from the calcination of a mixture of zirconia hydrosol, Ni salt, and a salt of cation stabilizing the tetragonal $\mathrm{ZrO}_{2}$ structure to form an oxide mixture of $\mathrm{NiO}$ and a tetragonal $\mathrm{ZrO}_{2}$ type multiple oxide, and finishing with a final reduction of surface $\mathrm{NiO}$ to form metallic nickel on the surface has proven to be ideal and promising for the mass production of the desired catalyst for $\mathrm{CO}_{2}$ methanation.

In this connection, the use of rare elements such as rare earth elements is not favorable for supplying fuel to the whole world. Instead of rare earth elements, the stabilization of the tetragonal $\mathrm{ZrO}_{2}$-type multiple oxide could be realized by the addition of $\mathrm{Ca}^{2+}$ or $\mathrm{Mg}^{2+}$. The authors have already found that the $\mathrm{CO}_{2}$ methanation activity of the best $\mathrm{Ni}-\mathrm{Zr}$-Ca catalyst prepared by the calcination of a mixture of zirconia hydrosol with $\mathrm{CaSO}_{4}$ and $\mathrm{NiSO}_{4}$ is higher than that of the best $\mathrm{Ni}-\mathrm{Zr}-\mathrm{Sm}$ catalyst.

\section{Toward the industrialization of global carbon dioxide recycling}

Based on the successful developments of key materials, we have installed a prototype plant of global $\mathrm{CO}_{2}$ recycling consisting of a photovoltaic cell, an electrolyzer, a $\mathrm{CO}_{2}$ methanation system, and a $\mathrm{CH}_{4}$ combustor from which $\mathrm{CO}_{2}$ is sent back to the $\mathrm{CO}_{2}$ methanation system, over the rooftop of the Institute for Materials Research, Tohoku University in 1995, as has been presented in Figure 12. This small-scale plant confirms that as long as solar energy is available, we can use solar energy in global $\mathrm{CO}_{2}$ recycling in distant combustion systems in the form of $\mathrm{CH}_{4}$ and do not emit $\mathrm{CO}_{2}$ into the atmosphere but can use $\mathrm{CO}_{2}$ repeatedly as a feedstock.

In 2003, a pilot plant on an industrial scale has been installed at the Tohoku Institute of Technology that was capable of generating $\mathrm{H}_{2}$ at a rate of $4 \mathrm{Nm}^{3} \mathrm{~h}^{-1}$ and $\mathrm{CH}_{4}$ at a rate of $1 \mathrm{Nm}^{3} \mathrm{~h}^{-1}$, as has been shown in Figure 13.

\section{Conclusions}

The basic technologies for realizing global $\mathrm{CO}_{2}$ recycling have already been in our hands. However, natural gas is readily available as a primary energy source nowadays but our methane is a quaternary energy formed by the conversion from solar energy via electricity and hydrogen. Each conversion requires cost, and hence our methane cannot compete at present with natural gas. However, as has been pointed out at the beginning of this review, the exhaustion of energy resources on the Earth is inevitable in the foreseeable future. Therefore, it is anticipated that in 15 to 20 years, countries possessing oil resources will start imposing limitations on the exports of their resources for their own survival. To face this severe reality straightforwardly, we have to develop alternative means to acquire energy on a large scale to sustain prosperity of our society. To the authors' knowledge, the proposed global $\mathrm{CO}_{2}$ recycling system is the most convenient alternative to acquire massive amounts of energy from renewable resources without being dependent on fossil or fissile mineral resources. 


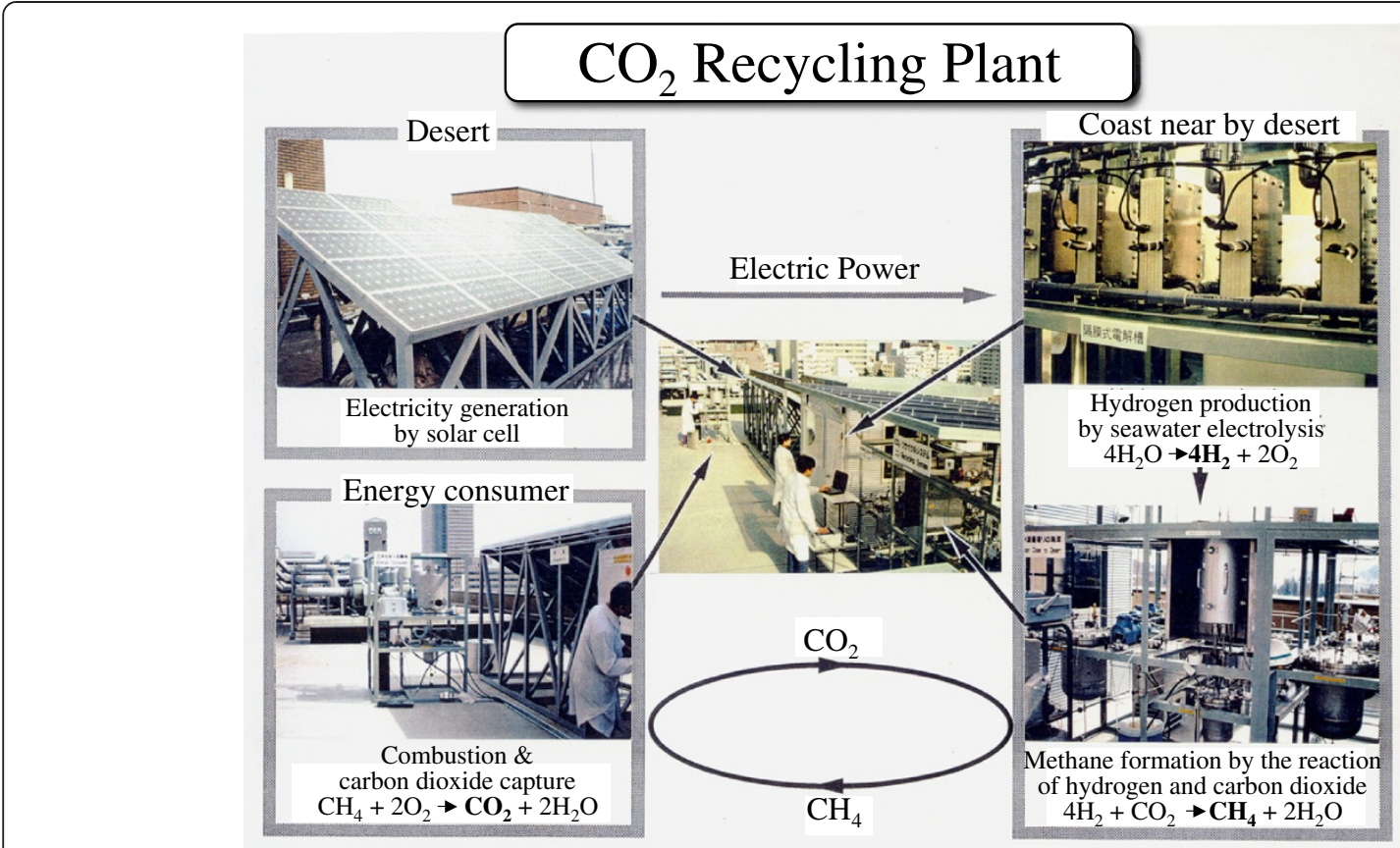

1995 at Institute for Materials Research, Tohoku University

Figure 12 A prototype plant of global $\mathrm{CO}_{2}$ recycling on the Institute for Materials Research, Tohoku University built in 1995.

The authors will continue to invest research efforts to improve the key materials and systems for the global $\mathrm{CO}_{2}$ recycling and to develop large-scale industrial plants based on this concept. Japanese and foreign firms have formed a joint development for the industrialization of global $\mathrm{CO}_{2}$ recycling plants in which they pay a particular attention to work without precious metals and rare elements. For a worldwide spread of technologies for the solution of global energy and related problems, we should never use precious metals and rare elements, considering always the total world reserves of the necessary elements for the spread of systems. Furthermore, we have succeeded in obtaining the maximum amount of methane from biomass by a combination of $\mathrm{CO}$ and $\mathrm{CO}_{2}$ methanation as well as a water-gas shift reaction of biomass-based syngas on our catalyst.

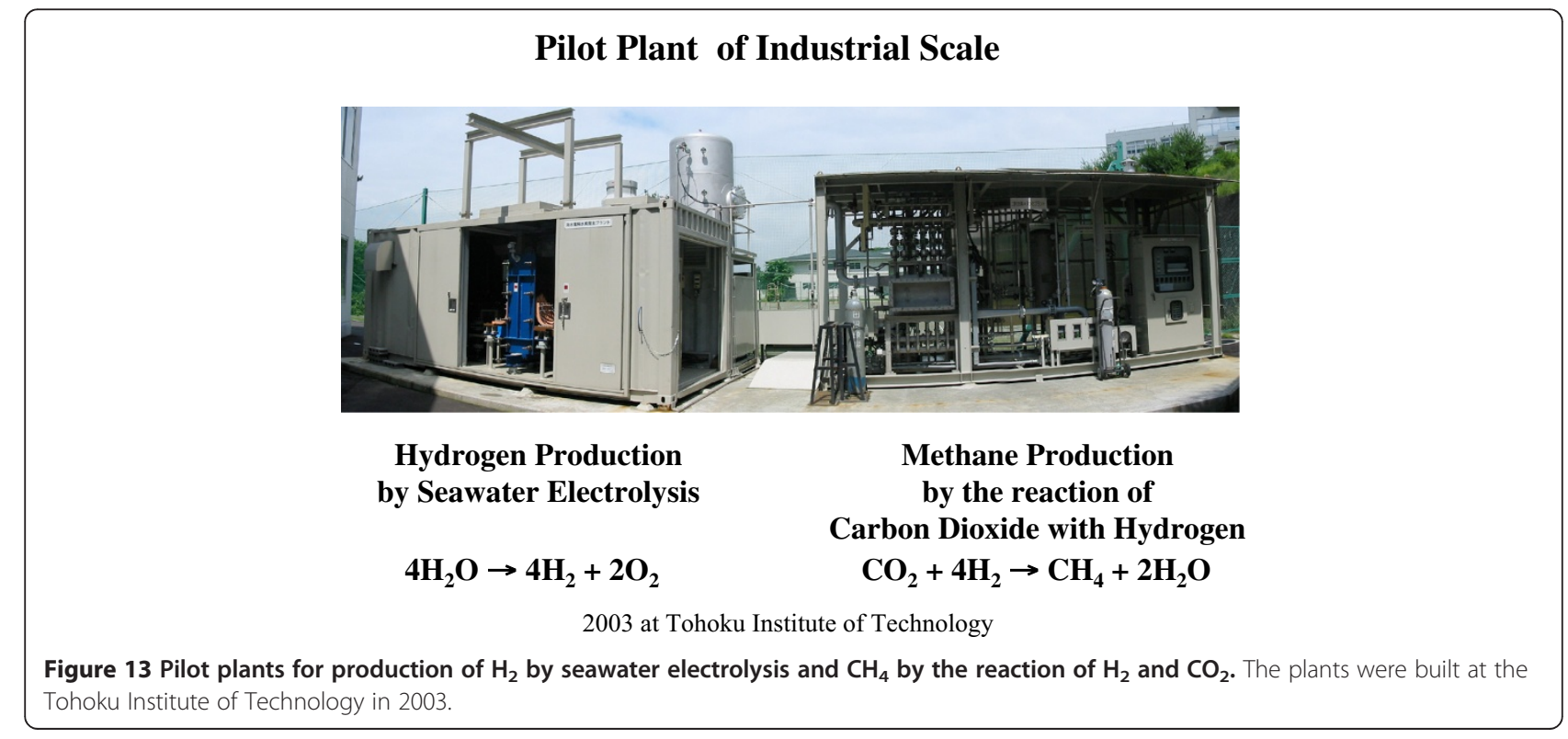




\section{Competing interests}

The authors declare that they have no competing interests.

\section{Authors' contributions}

This is the review of work done by the groups of $\mathrm{KH}$ for 25 years, to which several tens of scientists and engineers have been contributing. The names of authors listed in this article are now mostly contributing to the work and they read and approved the final manuscript.

\section{Author details}

${ }^{1}$ Tohoku Institute of Technology, Sendai 982-8577, Japan. ${ }^{2}$ Hitachi Zosen Corporation, 11 Shintoyohuta, Kashiwa 277-8513, Japan.

Received: 4 March 2014 Accepted: 8 July 2014

Published: 12 August 2014

\section{References}

1. http://www.eia.gov/tools/a-z/index.cfm (2013 version)

2. http://www.world-nuclear.org/info/inf75.html (2012 version)

3. http://www.re-policy.jp/keito/2/030912_09.pdf\#search (Tokyo Electric Powe Company, 2003)

4. Nakamura K (2003) http://www.re-policy.jp/keito/2/030912 06.pdf\#search

5. Habazaki H, Tada T, Wakuda K, Kawashima A, Asami K, Hashimoto K (1993) Amorphous iron group metal-valve metal alloy catalysts for hydrogenation of carbon dioxide. In: Clayton CR, Hashimoto K (eds) Corrosion, electrochemistry and catalysis of metastable metals and intermetallics. The Electrochemical Society, Princeton, pp 393-404

6. Hashimoto K (1993) Green materials - materials for global atmosphere conservation and abundant energy supply. Kinzoku (Materials Science \& Technology) 63:5-10. AGNE Gijutsu Center, Tokyo

7. Meguro S, Sasaki T, Katagiri H, Habazaki H, Kawashima A, Sakaki T, Hashimoto K (2000) Electrodeposited Ni-Fe-C cathodes for hydrogen evolution. J Electrochem Soc 147:3003-3009

8. Zabinski PR, Meguro S, Asami K, Hashimoto K (2003) Electrodeposited Co-Fe and Co-Fe-C alloys for hydrogen evolution in a hot $8 \mathrm{M} \mathrm{NaOH}$ solution. Mater Trans 44:2350-2355

9. Izumiya K, Akiyama E, Habazaki H, Kumagai N, Kawashima A, Hashimoto K (1998) Anodically deposited manganese oxide and manganese-tungsten oxide electrodes for oxygen evolution from seawater. Electrochim Acta 43:3303-3321

10. Fujimura K, Izumiya K, Kawashima A, Habazaki H, Akiyama E, Kumagai N, Hashimoto K (1999) Anodically deposited manganese-molybdenum oxide anodes with high selectivity for evolving oxygen in electrolysis of seawater. J Appl Electrochem 29:765-771

11. Abdel Ghany NA, Kumagai N, Meguro S, Asami K, Hashimoto K (2002) Oxygen evolution anodes composed of anodically deposited Mn-Mo-Fe oxides for seawater electrolysis. Electrochim Acta 48:21-28

12. El-Moneim AA, Kumagai N, Asami K, Hashimoto K (2006) New nanocrystalline manganese-molybdenum-tin oxide anodes for oxygen evolution in seawater electrolysis. ECS Trans 1(4):491-497

13. Kato Z, Kumagai N, Izumiya K, Hashimoto K (2011) Enhancement of durability of oxygen evolution anode in seawater electrolysis for hydrogen production. Appl Surf Sci 257:8230-8236

14. Yamasaki M, Habazaki H, Yoshida T, Akiyama E, Kawashima A, Asami K, Hashimoto K (1997) Composition dependence of the $\mathrm{CO}_{2}$ methanation activity of $\mathrm{Ni} / \mathrm{ZrO} 2$ catalysts prepared from amorphous $\mathrm{Ni}-\mathrm{Zr}$ alloy precursors. Appl Catal A, General 163:187-197

15. Yamasaki M, Habazaki H, Yoshida T, Komori M, Shimamura K, Akiyama E, Kawashima A, Asami K, Hashimoto K (1998) Characterization of $\mathrm{CO}_{2}$ methanation catalysts prepared from amorphous $\mathrm{Ni}-\mathrm{Zr}$ and $\mathrm{Ni}$-Zr-rare earth element alloys. Studies in Surf Sci Catal 114:451-454

16. Habazaki H, Yoshida T, Yamasaki M, Komori M, Shimamura K, Akiyama E Kawashima A, Hashimoto K (1998) Methanation of carbon dioxide on catalysts derived from amorphous $\mathrm{Ni}$-Zr-rare earth element alloys. Studies in Surf Sci Catal 114:261-266

17. Habazaki H, Yamasaki M, Zhang B-P, Kawashima A, Kohno S, Takai T, Hashimoto K (1998) Co-methanation of carbon monoxide and carbon dioxide on supported nickel and cobalt catalysts prepared from amorphous alloys. Appl Catal A, General 172:131-140
18. Habazaki H, Yamasaki M, Kawashima A, Hashimoto K (2000) Methanation of carbon dioxide on $\mathrm{Ni} /(\mathrm{Zr}-\mathrm{Sm}) \mathrm{O}_{x}$ catalysts. Appl Organometallic Chem 14:803-808

19. Takano H, Izumiya K, Kumagai N, Hashimoto K (2011) The effect of heat treatment on the performance of the $\mathrm{Ni} /(\mathrm{Zr}$-Sm oxide) catalysts for carbon dioxide methanation. Appl Surf Sci 257:8171-8176

doi:10.1186/s13705-014-0017-5

Cite this article as: Hashimoto et al:: The production of renewable energy in the form of methane using electrolytic hydrogen generation. Energy,

Sustainability and Society 2014 4:17.

\section{Submit your manuscript to a SpringerOpen ${ }^{\odot}$ journal and benefit from:}

- Convenient online submission

- Rigorous peer review

- Immediate publication on acceptance

- Open access: articles freely available online

- High visibility within the field

- Retaining the copyright to your article

Submit your next manuscript at $>$ springeropen.com 